
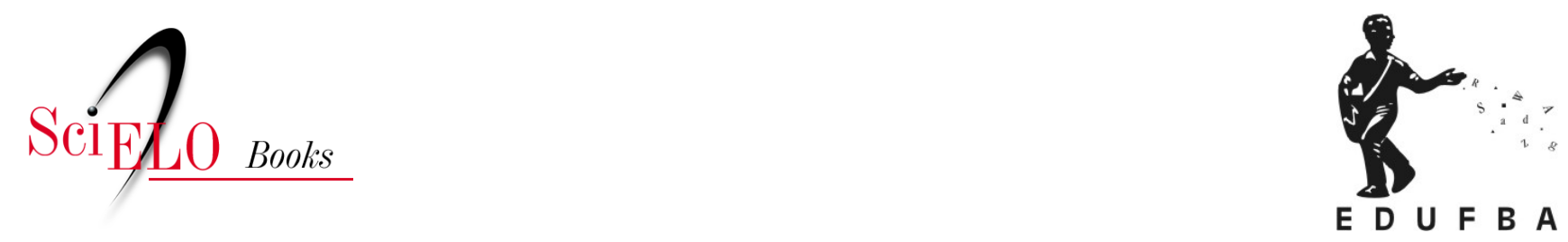

\title{
Os mineiros do amianto da lã do minério à contaminação do mal
}

\author{
Cláudia de Oliveira D’Arede \\ Maria do Carmo Soares de Freitas \\ Mônica Angelim Gomes de Lima
}

\section{SciELO Books / SciELO Livros / SciELO Libros}

D'AREDE, C.O., FREITAS, M.C.S., and LIMA, M.A.G. Os mineiros do amianto: da lã do minério à contaminação do mal. In: LIMA, M.A.G., FREITAS, M.C.S., PENA, P.G.L., and TRAD, S., orgs. Estudos de saúde, ambiente e trabalho: aspectos socioculturais [online]. Salvador: EDUFBA, 2017, pp. 145-156. ISBN: 978-85-232-1864-5. http://doi.org/10.7476/9788523218645.0008

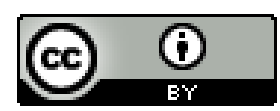

All the contents of this work, except where otherwise noted, is licensed under a Creative Commons Attribution $\underline{4.0 \text { International license. }}$

Todo o conteúdo deste trabalho, exceto quando houver ressalva, é publicado sob a licença Creative Commons Atribição 4.0. 


\title{
Os mineiros do amianto da lã do minério à contaminação do mal
}

\author{
CLÁUDIA DE OLIVEIRA D'AREDE \\ MARIA DO CARMO SOARES DE FREITAS \\ MÔNICA ANGELIM GOMES DE LIMA
}

\section{Introdução}

Este estudo descreve a transfiguração social das significações do amianto em uma comunidade de mineiros de Bom Jesus da Serra, Bahia, Brasil, apresentando esse minério como uma configuração do mal para o corpo e o lugar. Ou seja: uma contaminação ambiental e doenças em trabalhadores e suas famílias.

Entra em foco a contaminação do amianto, suas significações, o trabalho na mina, a noção do processo saúde-doença, riscos passados, presentes e futuros decorrentes da exposição a este minério que provoca asbestoses (doenças pulmonares obstrutivas crônicas) e canceres de pulmão, mesoteliomas de pleura e pericárdio.

A relação do homem com o amianto é antiga, pois ele é um facilitador da vida cotidiana, por suas principais características de isolante térmico e resistência às altas temperaturas, bem como, um elemento mágico e etiológico de doenças.

A Organização Mundial da Saúde (OMS) considera o amianto cancerígeno desde 1977 e estima que cerca de 107 mil trabalhadores morrem a cada ano no mundo por doenças causadas por esse minério. Na década de 
1990, a contaminação por amianto se tornou um problema de saúde pública em países da Europa, como a França, por exemplo, onde cerca de 100 mil pessoas poderão morrer de doenças relacionadas ao amianto até 2025 . As estimativas mostram que o câncer causado por amianto poderá matar na Europa Ocidental, aproximadamente 250 mil pessoas entre 1995 e 2029. O primeiro país europeu a banir este mineral foi a Noruega em 1984. Desde 2005, a fibra do amianto está banida em toda a Europa. Atualmente, está proibido em mais de sessenta países. (ABREA, 2010)

O Brasil é o terceiro produtor mundial, o segundo exportador e o quarto usuário de amianto. Produz mais de 250 toneladas por ano, perdendo para Rússia, Cazaquistão, China e Índia, respondendo por cerca de $10 \%$ de toda a produção mundial. A produção do tipo anfibólio, no Brasil, está banida desde 1991 pelo Ministério do Trabalho e Emprego, conforme Anexo 12 da NR15, que regulamentou e Convenção 162 da OIT e depois ratificou com a Lei 9055/95 que trata de coibir definitivamente o uso desse produto. Entretanto, há ainda uma mina de amianto no Brasil, localizada no município de Minaçu, Goiás. Ela produz amianto do tipo crisotila, terceiro maior produtor mundial, suprindo todo o consumo interno, e exporta para dezenas de países. Sua produção atinge aproximadamente 180.000 toneladas/ano. (PAMPLONA, 2003)

Até a década de 1930, o Brasil importava todo o amianto que consumia, principalmente do Canadá e África do Sul. (ABREA, 2010) Em 1939, com a descoberta do minério em São Félix, Bom Jesus da Serra, na época município de Poções, Bahia, dá início à exploração no Brasil. Esta mina, a cinco quilômetros da sede do município, permaneceu ativa até 1967, na época, com 548 trabalhadores. Em 2010, a população do município de Bom Jesus da Serra era de 10.550 (IBGE, 2010) e o Índice de Desenvolvimento Humano Municipal (IDHM) em 0,546, um dos menores da Bahia. Estando esse município, cerca de 120 quilômetros, distante da cidade mais importante do sudoeste baiano; Vitória da Conquista.

Diante do possível adoecimento de contaminação por amianto em mineiros de Bom Jesus da Serra, este estudo apresenta significados desse problema para as pessoas que viveram nesse ambiente da mineração, e abre a discussão sobre o tema da contaminação por amianto, questionando a ausência de políticas de saúde direcionadas a essa região. Para tanto, o estudo dá voz à singularidade da situação da exploração do amianto há mais de 40 anos, suas consequências e repercussões atuais. 
Foi necessário conhecer etnograficamente as mudanças nesta comunidade, onde ruas e casas são pavimentadas e construídas com o amianto; a mina abandonada hoje é lugar de lazer e pesca, mesmo com o processo do adoecimento dos mineiros e de suas famílias pela contaminação ambiental. Sobretudo, tornam-se visíveis as lembranças da “época da mina”, em um tempo e espaço no qual o amianto continua presente em suas vidas.

\section{Metodologia}

Trata-se de uma etnografia sobre os significados do amianto e a saúde dos mineiros de São Félix cujo procedimento metodológico requer o uso de diversas ferramentas, tais como: observação participante, entrevistas em profundidade, registro fotográfico e análise documental. Os roteiros de entrevistas abordaram fragmentos de histórias de vida dos mineiros, modos de viver e noções sobre saúde, processos de trabalho e questões sobre a contaminação pelo amianto.

A intenção desta pesquisa guarda relação com a compreensão do processo de construção da identidade social da comunidade de mineiros em relação ao trabalho no mundo da vida e o amianto. (DUARTE, 1986; LÉVI-STRAUSS, 1989) Assim, o esforço de envolver a experiência do convívio com as histórias dessas pessoas é revelado no trabalho de campo, com os escritos da escuta, das observações do cotidiano e as imagens registradas. Tudo gira em torno do processo de construção de uma identidade narrativa. (RICOEUR, 2009)

Nessa perspectiva, a pesquisa conversa sobre significados do amianto e a saúde para os mineiros e suas famílias, conjugando valores, costumes e práticas, percepções e representações sociais na continuidade e descontinuidade de um tempo vivido na mina ainda presente na memória destes protagonistas. A mina fechada na década de 1960 ainda apresenta resultados físicos da contaminação e subjetivos pelo medo de adoecer.

Semelhante condição foi observada por Eckert (2012) ao estudar a vida dos mineiros do carvão na França, em que se mostram significações de uma cultura repleta de representações e práticas de viver no mundo da mina.

Os mineiros de São Felix e suas famílias narram suas histórias de vida e trajetórias seguindo uma lógica temporal desde o funcionamento da mina ao momento atual, os impactos para o trabalho e a saúde. A experiência entre ser camponês e mineiro e vice-versa. 
Ao mergulhar no mundo desses mineiros e escutar suas vidas recordadas foi imaginável ir e vir no tempo com as longas entrevistas e as observações de campo percebendo seus caminhos narrados neste lugar que representam vida e morte, como se mostrará a seguir.

\section{O lócus etnográfico: a Mina de São Félix}

A exploração na mina de São Félix em Bom Jesus da Serra, Bahia, no período de 1939 a 1967, introduz subsequentes alterações nos modos de vida e costumes da comunidade: homens e mulheres transitaram das atividades tradicionais de agricultura de subsistência à extração do minério.

Com a mineração, vários mineiros buscaram se especializar na atividade de marteleteiro, quebrando pedra com o martelo no pilão para extração do minério, antes da chegada das máquinas de britagem, sendo essa uma das principais funções dos mineiros na época.

O ato da extração e exploração da terra, comum a todos os que se relacionam com ela, e a conscientização da contaminação, consequente ao ato de lidar com o amianto, aparecem como contradição da natureza.

O que "faz mal" é como um corpo simbólico presente na comunidade de Bom Jesus da Serra, que tem raízes em um imaginário coletivo do mundo da vida revelado como estranhamento da natureza.

O risco invisível do amianto para o corpo é como uma ameaça inevitável e recente. Em trinta anos de mineração, muitos trabalharam, adoeceram e morreram sem vincular a contaminação do minério ao adoecimento.

O minério tem lugar natural, mas a coexistência com o mundo dos homens agrega a falta de assistência e de informação e mantém a presença da empresa nas relações de poder e controle da saúde dos mineiros. Para estes, o perigo estava na usina de beneficiamento do amianto, da qual vinha a poeira branca que tudo cobria.

Poeira branca é o amianto propriamente, que contamina o corpo e o ambiente - plantações, animais, água e ar. A contaminação se revela no adoecimento, como sentido de perigo ameaçador. $\mathrm{O}$ risco acontece quando aparecem os sintomas, adoecimento e morte. Os sintomas referidos são: falta de ar, tosse, cansaço e mal-estar. A contaminação no corpo está no sentir-se sem forças pelo "mal do minério". As mortes dos parentes e amigos atribuídas ao amianto preenchiam o cotidiano do trabalho na mina e integravam 
o sentido de estranhamento com a tosse que os faziam cuspir lama. Ainda assim, ficavam sem proteção de serviços de saúde e a empresa os desinformava ao afirmar que "aquilo" - $o$ amianto - não fazia mal.

Na dimensão subjetiva, o amianto em Bom Jesus da Serra aparece nas falas dos mineiros de duas maneiras: como um agente natural e um mal. A montanha se transforma em mina que produz um pó branco que adoece $\mathrm{o}$ trabalhador e sua família. Entretanto, conforme suas narrativas, ninguém enxergava o mal, até surgir os primeiros casos de asbestose e câncer.

Antes, "o amianto não maltratava ninguém", até ser modificado pelo homem. Atualmente, após tantos anos do fechamento da mina, o lugar foi reinventado e incorporado à vida com atividades de lazer e história, ao lado do sofrimento, doenças, perigo e morte que ainda persistem. Pois, pessoas continuam morrendo de doenças associadas ao amianto.

Com o encerramento da mina, os mineiros voltaram a trabalhar apenas na roça, como seus antepassados. A pobreza é generalizada. Muitos estão aposentados como trabalhadores rurais, e sustentam a família inteira, filhos e netos, principalmente pela falta de geração de emprego na região. Complementam a alimentação - feijão, milho e mandioca - com o pouco que produzem nas roças e tantas vezes comem frutas - umbu, melancia - verdes, pois na necessidade de algo para comer não dá tempo para esperar que amadureçam. É situação de escassez de muitas necessidades básicas.

[...] Tinha roça, mesmo trabalhando na mina. Na semana que trabalhava de noite na mina, no correr do dia eu estava na roça. Se não fosse a lavoura, a gente sofreria mais. Quando a mineradora saiu daqui eu disse: 'não vou pra Goiás porque tenho minha família aqui, trabalho aqui, tenho a minha terra aqui, não vou'. (Aureliano)

[...] Hoje em dia, tem mês de comprar feijão, açúcar, café, óleo que não pode faltar. Mas nesse mês, nem o feijão, nem o arroz pude comprar. E a roça não está dando nada. Aí a gente pega uns pedacinho de carne, ou de fato, o que for, frita, fazfarofa e come. (Ilda)

A roça é a única perspectiva dessas pessoas conhecedoras dos ciclos naturais de chuvas e plantio, qualidade da terra. A atividade de mineiro foi aprendida paralelamente à atividade rural, representando um ofício a mais, entretanto para muitos não foi o principal ofício. Nesse sentido, a condição de camponês permanece. 
Este aspecto faz recordar a obra de Lévi-Strauss, $O$ pensamento selvagem (1989), sobre as sociedades tradicionais que veem a terra como um bem da natureza. $\mathrm{O}$ camponês não é o dono da terra, mas a utiliza para o plantio. Nesse aspecto, a mudança de clima é relacionada ao sagrado e o surgimento do "homem sabido" faz relação com o destruidor. O que chegou de fora e implantou a mineradora trazendo doenças, perigo e morte. Destruiu a quietude do lugar e mudou o tempo.

Os camponeses-mineiros entendem que ao modificar a natureza, a mineradora se apoderou do amianto, que antes não fazia mal, e passou a atingir o homem e o clima, afetando a roça.

Os mineiros trabalharam dentro e fora da montanha, permitindo-lhes um conhecimento para além da condição de agricultores. Com isso, percebem, relatam e interpretam o mundo do trabalho com símbolos e significados próprios e socialmente compartilhados. $\mathrm{O}$ amianto estava intacto dentro da montanha e foi mexido, trazendo o mal para a vida do lugar.

Como parte da vida, sentem-se camponeses e mineiros, sem separação. Seguem hoje como camponeses, mesmo aposentados, e recorrem às lembranças da mina, do trabalho com os vagões, o "marrão" (martelo), a "cama de poeira” (câmara de poeira) e a retirada da lã do minério das pedras. São homens e mulheres do campo que não conseguiram, a partir do trabalho na mina, qualquer resultado prático dos direitos trabalhistas contemplados nesta atividade.

[...] Na usina, eu trabalhava na água, de meio dia pra tarde, ia pro fundo da usina pra pegar a produção do vagão, pra entregar no escritório. Quando o vagão de minério saía, passava ali, pesava o de rejeito,jogava pra cá aquela banca que tinha cá. No outro dia, eram outros, de manhã até meio dia, depois outros vinham pra botar água de meio dia pra tarde, era assim. Até que chegou a um ponto que eu fui pro corte, depois mejogaram pra pedreira, levando minério pro galpão pra quando chovesse a usina não parasse, pra ter minério seco, outra hora trabalhava no minério, furando pedra. E aí ninguém levou a sério isso. Deixou prejudicar demais, alguns tinham febre, uns morriam, chegavam a amarelar. (Antônio, mineiro)

\section{O mal do minério: "a placa pleural"}

Antes mesmo de analisar as narrativas dos mineiros de São Felix, vale recordar alguns autores e noções sobre o processo interpretativo do adoecimento. Para Alves (2006) a doença é um fenômeno que diz respeito a um conjunto de 
elementos socioculturais interligados; sickness refere-se ao mundo da doença, isso é, um horizonte de significados, condutas e instituições associadas à enfermidade ou ao sofrimento.

Para B. Good e M. Good (1980) a enfermidade é também uma construção social a partir das teorias e redes de significados que compõem as diferentes subculturas. Nesse sentido, a enfermidade é essencialmente semântica e a transformação da doença em experiência humana é objeto do sentido. Assim, a enfermidade é uma experiência dotada de sentido para cada sujeito particular. A ideia de enfermidade como "rede semântica", realidade construída através do processo de interpretação/significação, se fundamenta na rede de significados que estrutura a própria cultura. São estruturas profundas que ligam enfermidades a valores culturais fundamentais de uma cultura, permanecendo, ao mesmo tempo, fora do conhecimento cultural explícito e da consciência dos membros que compõem a sociedade, apresentando-se como naturais. (GOOD, 1994, p. 172)

A partir destes conceitos, tenta-se entender a realidade sobre a relação do homem com o amianto, seus significados, e conhecer a noção do processo saúde/doença, riscos passados, presentes e futuros decorrentes da exposição a esse minério.

Para os mineiros, seus sintomas de adoecimento não eram e ainda nem sempre são considerados pelo serviço de saúde da empresa. Para os mineiros, a doença é interpretada através da simbologia: "um mal dentro do corpo com uma fôrma"; o minério guardado no corpo, em algum momento, pode se manifestar. A ameaça do adoecimento é percebida através do ar, o condutor do amianto no corpo. $\mathrm{O}$ lugar em que nasceu, e vive atualmente, passa a ter um sentido ameaçador e convive-se com esta ameaça, o risco. Passam a conviver com o estigma social do lugar, como se vivessem em perigo permanente para asbestose e câncer de pulmão. Doenças que se manifestam muitos anos depois do contato, e o risco ambiental continua com a poeira do amianto.

Os padrões culturais que as pessoas utilizam para interpretar um dado episódio de doença são criações sociais, interpretações construídas intersubjetivamente. Só dentro das coordenadas estabelecidas pelo mundo intersubjetivo do senso comum é que a experiência da enfermidade é admitida como fato evidente. (SCHUTZ, 1979) A enfermidade, subjetivamente dotada de sentido, é afirmada como real para os membros da sociedade e entendida como experiência individual e coletiva simultaneamente. 
[...] Tenho minério guardado no corpo, quando vai aparecer esse mal que está guardado, a gente não sabe. (Deco, mineiro)

A gente está respirando o pó. Aié difícil. Às vezes, eu penso muito em sair daqui, mas qual é a condição que eu tenho de sair daqui? (Damião, mineiro)

[...] Esse pó é tão forte, que quando a pessoa gripava, era ofedor do pó, era aquele mau cheiro de pó, ninguém aguentava o cheiro. Ele tinha um cheiro forte diferente, parecido com água sanitária. (D. Bina)

Antigamente, era mais pó do que terra que forrava essas estradas. (Seu Alberto)

De dez da noite às seis da manhã, poeira, poeira, poeira! A gente não pensava. Era normal. Quando a gente escarrava, só saía a poeira. De lá tacava nas peneiras, e a poeira subia direto. Era muita gente, muita gente cuspindo sangue com poeira, tossindo. (Clemente, mineiro)

Para os mineiros de Bom Jesus da Serra, a experiência comum revela na linguagem o vento como o condutor da ameaça da contaminação de amianto que produz enfermidades. A sensação de se sentir mal se encontra intrinsecamente acompanhada de uma compreensão do seu significado: o pó do amianto que adoece e mata.

Está em jogo as forças da natureza como o vento e a pouca chuva no lugar semiárido que espalha o "pó que faz mal”. Assim, os modos interpretativos sobre o aparecimento das doenças relacionadas ao amianto, submetem-se às estruturas de pensar o trabalho, a natureza, a sobrevivência, a tradição dos familiares.

Alves (1993, p. 269) relata que uma enfermidade se constitui como uma interpretação, um julgamento cujo componente subjetivo “[...] está fundamentado no ato individual de perceber a experiência interior como problemática, [mas] a construção [...] desta experiência não ocorre como um processo isolado”.

Conforme a narrativa dos mineiros de São Felix a doença,

Começa pelos lábios. Vai ficando com os lábios secos, não saliva mais, vai ficando com os pulmões. Porque a gente tem esse processo de inspirar, encher os pulmões. O portador de asbestose não consegue fazer isso; então ele morre asfixiado, praticamente asfixiado, por não conseguir respirar, é horrível! [...] Meu pai falava da dificuldade pra respirar. Ele andava 50 metros, 10, 15 minutos, descansava, depois andava mais um pouquinho e sentava. Porque, 
mesmo doente, ele tentava andar. E minha mãe morreu antes, com os mesmos sintomas, cansaço, que nem o meu pai. (Osvaldo, mineiro)

[...] O que mudou na minha vida foi perder a minha saúde. Eu sinto uma falta de ar, um 'avexamento' assim por dentro, e depois que eu fiz esse exame o médico disse que eu estava com inflamação no intestino, eu sinto uma dor aqui debaixo da costela, não durmo bem, já perdi cinco quilos. (Aureliano, mineiro)

Ter perdido a saúde por causa do trabalho na mina e a impossibilidade de se dedicar mais às atividades na roça constituem em impactos da enfermidade na vida dessas pessoas em todas as suas dimensões.

A placa pleural é uma atribuição médica incorporada à cultura local, uma doença não explicada. Algo que poderá crescer ou não, mas que dá visibilidade à presença da contaminação no corpo. Uma placa dentro do corpo, visível ao exame médico e presente também em outros, concretiza a ameaça, mas também a semelhança entre os mineiros da mina de São Félix:

Eu sinto uma dor do lado, parece que o minério está pregado, eles disseram que é a placa do minério que entrou e ficou, e eu estou sentindo agora. Tenho que fazer exame pra ver a placa pleural. E o meu irmão João disse que também tem. (Alberto, mineiro)

[...] Sinto um cansaço, uma tristeza. Eu trabalhei muito tempo naquela mina pras 'madames' que vinham da França. Tive um entupimento no nariz, pela lã (ou pó) do amianto que entra na gente, é doença do homem. (Vitória, viúva de ex-mineiro)

O mal do minério possui significado de placa pleural, termo absorvido por eles, como uma doença que entra no corpo através da lã ou fibra, pó ou poeira, deixado pela empresa no passivo ambiental da mina abandonada. Os mineiros do amianto buscam tratamento nos serviços de saúde locais e outros alternativos. Inicialmente, quando apareceram os sintomas de abestose, como cansaço, tristeza e tosse, os trabalhadores e suas famílias passaram a fazer tratamentos caseiros, indicados por “métodos encantados” $\mathrm{e}$ com a fé no sagrado. Usavam e ainda usam ervas como sabugueiro, urso etc.

Também, algumas mulheres adoeceram, pois lavavam as roupas dos maridos e sentiam a presença do amianto no corpo. Para elas, a placa pleural é a doença da contaminação do minério no corpo. Uma placa dentro do corpo, visível ao exame médico é uma ameaça concreta semelhante entre os mineiros da mina de São Félix. 
As doenças mais comuns causadas pela fibra mineral são as doenças do pulmão, asbestose - conhecida como "pulmão de pedra", na qual o doente é lentamente levado à morte por asfixia - e o mesotelioma - um tumor maligno, agressivo e letal na maioria dos casos, conhecido como o "câncer do amianto". Como um agente potencialmente cancerígeno a fibra do amianto presente no pulmão configura-se como uma ameaça permanente para $\mathrm{o}$ adoecimento e a morte.

\section{Conclusão}

[...] Eu acho que todos que entram naquela área, que moram no entorno da mina, estão correndo um grande risco de serem contaminados. Se num momento a gente inala uma fibra o câncer está garantido. Não tem como controlar. Porque nada destrói o amianto. Se você pegar uma fibra de amianto e levar ao fogo, ela fica em brasa e aí volta ao estado normal. É como se nada tivesse acontecido; então, qual o medicamento pra destruir um trem desse? Então, eu acredito que tem muita gente contaminada aqui na região e que se não tirar esse amianto aí rapidinho, ele vai contaminar muita gente. (Representante local da Associação Baiana dos Expostos ao Amianto - ABEA)

A exploração na mina de São Félix em Bom Jesus da Serra, Bahia, no período de 1939 a 1967, induziu subsequentes alterações nos modos de vida da comunidade: homens e mulheres que transitaram das atividades tradicionais de agricultura de subsistência à extração do minério.

O risco invisível de adoecimento associado ao minério coexiste há 70 anos com a falta de assistência à saúde e de informações sobre o controle da saúde dos mineiros.

A convivência com o amianto, ou a 'pedra cabeluda' como a nomeiam, é para alguns, naturalizada como um objeto comum do lugar, e para outros uma ameaça à vida. Para alguns o perigo estava na usina de beneficiamento do amianto, de onde vinha a lã ou poeira branca que tudo cobria. E a contaminação se revela apenas no adoecimento. Antes, sem sintomas nada parecia ameaçar. Ao surgirem os primeiros casos, os mineiros aprendem a associar o amianto às doenças e óbitos dos companheiros da mineração.

Ainda sentem "uma coisa estranha", "uma tosse”, e relembram o trabalho sem proteção alguma e a mensagem enganosa da empresa. Ao encobrir a 
informação sobre o dano à saúde e manter a exploração da mina, a empresa SAMA se torna responsável pelo crime ambiental.

Segundo Beck (2010), o risco é invisível na modernidade. Atualmente, o risco invisível do amianto está presente nos discursos dos filhos dos mineiros ao se recordarem e dos netos que ainda brincam com as pedras do minério.

Apesar desse quadro de morbidades gravíssimas: asbestoses - doenças pulmonar obstrutivas crônicas - e canceres de pulmão, mesoteliomas de pleura e pericárdio empresa e Estado os abandonaram. O movimento social dos mineiros, Associação Baiana dos Expostos ao Amianto (ABEA), denuncia permanentemente a situação desses mineiros e de suas famílias e tenta resgatar os direitos previdenciários das vítimas.

A ABEA funciona como único movimento contrário à SAMA na busca por indenizações e planos de saúde para todos os mineiros e tem ao longo do tempo encontrado embates com o poder judiciário. Uma ação civil pública movida pelo Ministério Público Estadual e Federal, através da ABEA e Associação Brasileira de Expostos ao Amianto (ABREA) em 2008, cuja medida visa dar cumprimento à determinação da justiça federal de Vitória da Conquista obrigou o Estado, os municípios e a empresa SAMA a cumprirem algumas obrigações, como por exemplo: o cadastramento dos trabalhadores e familiares pela exposição ocupacional e ambiental, e a composição de junta médica pela Secretaria de Saúde do Estado da Bahia para realização de exames de saúde dos trabalhadores. Outra ação civil pública ambiental ainda está em curso para obrigar a referida empresa a reparar danos ambientais.

\section{Referências}

ASSOCIAÇÃO BRASILEIRA DE EXPOSTOS AO AMIANTO - ABREA. História do Amianto. Osasco, 2010. Disponível em: <http://www.abrea.org.br/o-amianto/ hist\% 3 \%B3ria-do-amianto.html>. Acesso em: 22 abr. 2010.

ALVES. P. C. A experiência da enfermidade: considerações teóricas. Cadernos de Saúde Pública, Rio de Janeiro, v. 9, n. 3, p. 263-271. jul./set. 1993.

ALVES. P. C. A fenomenologia e as abordagens sistêmicas nos estudos sócioantropológicos da doença: breve revisão crítica. Cadernos de Saúde Pública, Rio de Janeiro, v. 22, n. 8, p. 1547-1554, ago. 2006.

BECK, H. Sociedade de risco: rumo a uma outra modernidade. São Paulo: Ed. 34, 2010. 
DUARTE, L. F. D. Da vida nervosa: nas classes trabalhadoras urbanas. Rio de Janeiro: Zahar; Brasília: CNPq, 1986.

ECKERT, C. Memória e trabalho: etnografia da duração de uma comunidade de mineiros de carvão (La Grand-Combe, França). Curitiba: Appris, 2012. (Ciências sociais).

IBGE. Censo Demográfico 2010. Rio de Janeiro, 2010.

GOOD, B. Medicine, rationality, and experience: an anthropological perspective. Cambridge: Cambridge University Press, 1994.

GOOD, B.; GOOD, M. J. D. The meaning of symptoms: a cultural hermeneutic model for clinical practice. In: EINSERBERG, L.; KLEINMAN, A. (Ed.). The relevance of social science for medicine. Boston: D. Reidel Publishing Company, 1980.

LÉVI-STRAUS, C. O pensamento selvagem. Campinas, SP: Papirus, 1989.

PAMPLONA, R. I. O amianto crisotila e a SAMA: 40 anos de história Minaçu-Goiás: da descoberta à tecnologia limpa: 1962-2002. Minaçu, 2003.

RICOEUR, P. Teoria da interpretação: o discurso e o excesso de significação. Lisboa: Edições 70, 2009. (Biblioteca de filosofia contemporânea, n. 2).

SCHUTZ, A. Ação no mundo da vida. In: WAGNER, H. R. (Org.). Fenomenologia e relações sociais: textos escolhidos de Alfred Schutz. Rio de Janeiro: Zahar, 1979. p. 120-140. 